\title{
Removal of toxic metal ions from wastewater by semiconductor photocatalysis
}

\author{
Dingwang Chen, Ajay K. Ray* \\ Department of Chemical and Environmental Engineering, National University of Singapore, 10 Kent Ridge Crescent, Singapore 119260, Singapore
}

\begin{abstract}
Semiconductor photocatalytic reduction is a relatively new technique for the removal of dissolved metal ions in wastewater. In this paper, physical adsorption and photocatalytic reduction of eight environmentally significant metal ions in $\mathrm{TiO}_{2}$ suspensions of Degussa P25 and Hombikat UV100 were investigated. Critical scrutiny of the potential versus pC and pH diagrams reveals that any particular oxidation or reduction reaction can be promoted thermodynamically over other reactions by adding different reactants. In order to elucidate better understanding of the kinetics of the photocatalytic process, operating parameters such as dissolved oxygen, presence of ferric and ferrous ions, organic reductants and their concentrations were examined in detail. It was observed that the presence of dissolved oxygen inhibits while the presence of organic reductants promotes photocatalytic reduction. (C) 2001 Elsevier Science Ltd. All rights reserved.
\end{abstract}

Keywords: Environment; Kinetics; Reaction engineering; Multiphase reactions; Titanium dioxide; Photocatalytic reduction

\section{Introduction}

Metal ions are generally non-degradable. They have infinite lifetimes, and build up their concentrations in food chains to toxic levels. In recent years, arrays of industrial activities have been disturbing the geological equilibrium of metal ions through release of large quantities of toxic metal ions into the environment. It is well known that $\mathrm{Hg}(\mathrm{II}), \mathrm{Pb}(\mathrm{II}), \mathrm{Cd}(\mathrm{II}), \mathrm{Ag}(\mathrm{I}), \mathrm{Ni}(\mathrm{II})$ and $\mathrm{Cr}(\mathrm{VI})$ are very toxic among the metal ions present in the environment. Mercury is extensively used in electrical equipment (such as batteries and relays), metallurgy, catalysts, paint and colour industry, fungicides, herbicides and insecticides, etc. Lead is present in soil at varying concentration levels. It is also found in vehicle exhausts, used motor oil, insecticides, and paints. Cadmium, silver, nickel and chromium are widely used in electroplating industry as a protective coating for iron and steel, and in alloys with other metals. Silver is also commonly found in the wastewater of photographic industry. As a result, in today's highly industrialized society we are living in an environment with a multitude of potentially harmful toxic metal ions.

\footnotetext{
*Corresponding author. Tel.: + 65-874-8049; fax: + 65-779-1936.

E-mail address: cheakr@nus.edu.sg (A.K. Ray).
}

In contrast, the demand for metals increases significantly with the development of industry. Thus, waste metal recovery can potentially resolve two issues: metals pollution prevention and simultaneously, resource conservation. Precipitation, activated carbon adsorption, ion exchange, and membrane separations are common methods currently adopted for the disposal or recovery of metal ions in wastewater (Serpone, Boragarello, \& Pelizzetti, 1988). All these methods have their own advantages and disadvantages. The source of wastewater and the concentration level of contaminants are the two main factors that influence the efficiencies of the above methods.

Reduction by semiconductor photocatalysis technology (Chen, Sivakumar, \& Ray, 2000a) is a relatively new technique for the removal or recovery of dissolved metal ions in wastewater. The process couples low-energy ultraviolet light with semiconductor particles acting as catalyst and is based on the reduction by the photogenerated electrons. When semiconductor particles are illuminated by ultraviolet light with energy greater than the bandgap energy of the photocatalyst, electron/hole pairs are generated within the catalyst particles (Chen et al., 2000a). As reported in our previous papers (Chen \& Ray, 1998,1999), reduction by photogenerated electrons takes place concurrently with oxidation by the photogenerated holes in a heterogeneous photocatalytic 
process. When electron scavenger, such as oxygen, is used to suppress electron/hole recombination, and to allow the photogenerated holes to undergo the anodic reactions, it is called the photocatalytic oxidation. By contrast, photocatalytic reduction takes place when hole scavenger is adopted, and the photogenerated electrons are allowed to undergo cathodic reactions. A potential and very attractive practical application of light-driven photocatalytic reduction is the deposition of environmentally harmful toxic metals, and recovery of noble metals from industrial waste effluents. The metals are deposited onto the surface of semiconductor catalyst powders, and can subsequently be extracted from the slurry by mechanical and/or chemical means.

Prairie, Evans, Stange, and Martinez (1993) investigated the photocatalytic reduction of a variety of dissolved metal ions in $0.1 \mathrm{wt} \% \mathrm{TiO}_{2}$ (Tioxide Tilcom HACS, $270 \mathrm{~m}^{2} / \mathrm{g}$ ) suspensions. They found that only those metals with half-reaction standard reduction potentials more positive than $0.3 \mathrm{~V}$ could be reduced using $\mathrm{TiO}_{2}$ as photocatalyst. Photocatalytic reduction of $\mathrm{Ag}(\mathrm{I})$ (Herrmann, Disdier \& Pichat, 1988), Au(III) (Prairie et al., 1993), Cr(VI) (Fu, Lu \& Li, 1998; Khalil, Mourad, \& Rophael, 1998), $\mathrm{Hg}(\mathrm{II})$ (Serpone et al., 1987), $\mathrm{Pb}(\mathrm{II})$ (Tennakone \& Wijayantha, 1998), Mn(II) (Tanaka, Harada, \& Murata, 1986) and Pt(IV) (Angelidis, Koutlemani \& Poulios, 1998) was investigated and reported in the literature. $\mathrm{Ag}(\mathrm{I}), \mathrm{Au}(\mathrm{III}), \mathrm{Hg}(\mathrm{II})$ and $\mathrm{Pt}(\mathrm{IV})$ could also be reduced to corresponding metals, and be eliminated efficiently by depositing them onto the photocatalyst surface. $\mathrm{Cr}(\mathrm{VI})$ was reduced to $\mathrm{Cr}(\mathrm{III})$, and subsequently, removed in alkaline medium by precipitation as $\mathrm{Cr}(\mathrm{OH})_{3}$. However, no reduction for $\mathrm{Cd}(\mathrm{II})$ and Ni(II) (Prairie et al., 1993) was observed. Photocatalytic reduction of $\mathrm{Cu}$ (II) was a controversial topic. Reiche, Dunn and Bard (1979) investigated the photoreduction of $\mathrm{Cu}(\mathrm{II})$ in $\mathrm{TiO}_{2}$ suspensions. They observed complete reduction of $\mathrm{Cu}$ (II) to copper metal in aqueous solutions containing either acetate or no organic species. Bideau, Clandel, Faure and Rachimoellan (1990) observed the formation of a red $\mathrm{Cu}-\mathrm{TiO}_{2}$ species when solution containing $\mathrm{Cu}$ (II) and formate was illuminated in the presence of $\mathrm{TiO}_{2}$. Complete reduction of $\mathrm{Cu}$ (II) was also observed by Wang and Wan (1994) in UV illuminated $\mathrm{TiO}_{2}$ suspensions containing methanol, although, no reduction was possible in the absence of methanol. Foster, Noble and Koval (1993) reported that $\mathrm{Cu}(\mathrm{II})$ could be reduced to $\mathrm{Cu}(\mathrm{I})$ only in the presence of suitable organics, such as sodium formate and EDTA, and complete reduction was not observed. As for photocatalyst, $\mathrm{TiO}_{2}$ was extensively used in the above investigations (Chen et al., 2000a). In some studies, CdS (Wang, Wang \& Zhuang, 1992) and ZnO (Selli, Giorgi \& Bidoglio, 1996; Khalil et al., 1998) were also tested.

In the present paper, we report photocatalytic reduction of environmentally interested metal ions in $\mathrm{TiO}_{2}$ suspensions. Two brands of commercially available $\mathrm{TiO}_{2}$, Degussa P25 and Hombikat UV100, were chosen as semiconductor photocatalysts for comparative study. It is widely known that Degussa P25 TiO 2 catalyst outperforms all other $\mathrm{TiO}_{2}$ catalysts for photocatalytic degradation of toxic chemicals. However, a recent study (Ray \& Beenackers, 1997a,b) showed that for a textile dye pollutant UV100 $\mathrm{TiO}_{2}$ catalyst has higher activity over Degussa $\mathrm{P} 25 \mathrm{TiO}_{2}$ for all values of catalyst layer thickness and light intensities except when catalyst layer is very thin and UV light used is at low intensity. The observed rate increase was due to higher specific surface area of UV100 (5 times more compared to Degussa P25) catalyst (see Table 1). However, the observed increase in rate was found out to be not true for all pollutants due to poor light absorbing and adsorption characteristics of UV100 catalyst compared to Degussa P25 (Chen, Fengmei \& Ray, 2000b).

It should be noted that solid photocatalyst particles could be dispersed (Chen \& Ray, 1998,1999) or immobilized within the reactor (Ray, 1998,1999). In numerous investigations, an aqueous suspension of the catalyst particles in immersion or annular type photoreactor has been used. However, the use of suspensions requires separation and recycling of the ultrafine catalyst from the treated liquid and can be an inconvenient, time-consuming expensive process (Ray \& Beenackers, 1997b). In addition, the depth of penetration of UV light is limited because of strong absorption by both catalyst particles and dissolved organic species (Ray \& Beenackers, 1997a). The above problems could be avoided in photoreactors in which photocatalyst particles are immobilised onto a fixed transparent surface, such as the reactor wall or structures that are held in fixed positions in the photoreactor (Ray \& Beenackers, 1998). However, immobilisation of catalyst on a support generates a unique problem (Ray, 2000). The reaction occurs at the liquid-solid interface and usually only a part of the catalyst is in contact with the reactant. Hence, the overall rate is limited to mass transport of the pollutant to the catalyst surface (Periyathamby \& Ray, 1999). In addition, the rate of reaction is usually slow because of the low concentration level of the pollutant and, therefore, there is a need for a reactor whose design provides a high ratio of illuminated immobilised catalyst to illuminated surface and provides the possibility of total reactor illumination. The major challenges in the design of photocatalytic reactor have been discussed recently (Mukherjee \& Ray, 1999).

On the basis of thermodynamic analysis, the possibilities of photocatalytic reduction for metal ions of interest were discussed. Physical adsorption of metal ions on the above two brands $\mathrm{TiO}_{2}$ in aqueous systems containing 4-nitrophenol was also investigated. In order to understand the photocatalytic process, experiments were performed in the presence and/or absence of dissolved 
oxygen, ferric and ferrous ions, and organic reductants at different concentration levels.

\section{Thermodynamic analysis}

The extent of removal of metal ions and potential use under various solution conditions has not been investigated systematically. The mechanism of photocatalytic reduction of dissolved metal ions is still not very clear, but the redox process is always outlined as follows: metal ions are reduced by capturing the photo-excited conduction band electrons, and water or other organics are oxidized by the valence band holes. Therefore, the following redox reaction cycle takes place:

$$
\begin{aligned}
& \mathrm{TiO}_{2} \stackrel{h v \geqslant E_{b g}}{\rightarrow} \mathrm{TiO}_{2}\left(\mathrm{~h}^{+}+\mathrm{e}^{-}\right) \\
& \mathrm{M}^{n+}+\mathrm{e}^{-} \rightarrow \mathrm{M}^{(n-1)+} \\
& \mathrm{OH}^{-}+\mathrm{h}^{+} \rightarrow \mathrm{OH}^{\bullet} \\
& \mathrm{OH}^{\bullet}+\mathrm{RH} \rightarrow \mathrm{R}^{\bullet}+\mathrm{H}_{2} \mathrm{O} \\
& \rightarrow \mathrm{CO}_{2}+\mathrm{H}_{2} \mathrm{O}+\text { mineral acids } \\
& 2 \mathrm{H}_{2} \mathrm{O}+4 \mathrm{~h}^{+} \rightarrow \mathrm{O}_{2}+4 \mathrm{H}^{+}
\end{aligned}
$$

where $\mathrm{M}$ represents the metal ion. In the presence of organic species $\mathrm{RH}$, the photogenerated holes in Eq. (1) are consumed through reactions (3) and (4) to keep the system's neutrality. If no organics are present, water will be oxidized by reaction (5), and at this point, photocatalytic reduction of metal ions in reaction (2) may be limited by the low rate of water oxidation. Therefore, if one is interested to promote one reaction (oxidation or reduction) over the other, one should conduct experiments in presence or absence of certain species in order to make a particular reaction thermodynamically more favourable over the other. This can be explained from potential versus $\mathrm{pH}$ and $\mathrm{pC}$ diagrams.

In order to photoreduce a chemical species, the conduction band of the semiconductor photocatalyst must be more negative than the reduction potential of the chemical species. By contrast, only when the potential of the valence band is more positive than the oxidation potential of the chemical species, photo-oxidation can occur. Therefore, the energy level of the bottom of the conduction band is a measure of the reduction strength of the photogenerated electrons. Fig. 1 illustrates the positions of valence and conduction bands of anatase $\mathrm{TiO}_{2}$ photocatalyst in contact with an aqueous electrolyte solution at different $\mathrm{pH}$, and compares them with the reduction potentials of relevant environmentally important metal ions. It is worth noting that the positions of both conduction and valence bands are $\mathrm{pH}$ dependent. The increase of $\mathrm{pH}$ in electrolyte solution makes the

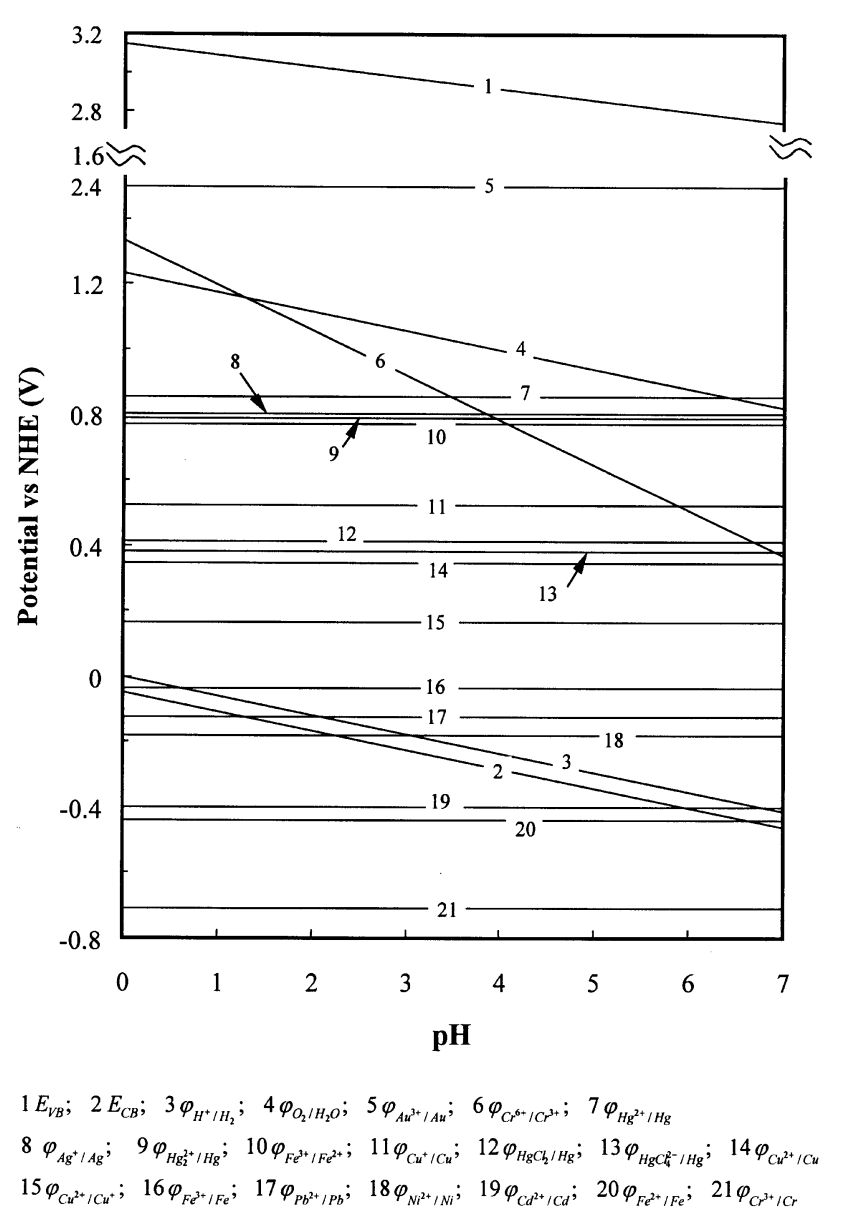

Fig. 1. Positions of valence and conduction bands of $\mathrm{TiO}_{2}$ (anatase) together with the reduction potentials of metal ions $(1 \mathrm{M})$ of interest at different $\mathrm{pH}$ (calculated from the Nernst equation).

positions of the valence and conduction bands to shift to more cathodic potentials by $59 \mathrm{mV}$ per $\mathrm{pH}$ unit (Ward, White \& Bard, 1983).

$$
\begin{aligned}
& E_{C B}(V)=-0.05-0.059 \mathrm{pH} \quad\left(\text { at } 25^{\circ} \mathrm{C}\right), \\
& E_{V B}(V)=3.15-0.059 \mathrm{pH} \quad\left(\text { at } 25^{\circ} \mathrm{C}\right) .
\end{aligned}
$$

However, as illustrated in Fig. 1, reduction potentials of all metal ions (except for $\mathrm{Cr}(\mathrm{VI})$ ) are independent of $\mathrm{pH}$. Consequently, photocatalytic reduction of these metal ions is favoured at high $\mathrm{pH}$. Moreover, the photogenerated electrons may reduce protons, water, dissolved oxygen, or metal ions, depending on the solution conditions. On the basis of Fig. 1, one can see that $\mathrm{Cd}(\mathrm{II})$, $\mathrm{Fe}(\mathrm{II})$ and $\mathrm{Cr}$ (III) cannot be photocatalytically reduced because their reduction potentials are more negative than that of photogenerated electrons. However, photocatalytic reduction of $\mathrm{Au}(\mathrm{III}), \mathrm{Cr}(\mathrm{VI}), \mathrm{Hg}(\mathrm{II})$ (including $\mathrm{HgCl}_{2}, \mathrm{HgCl}_{4}^{2-}$ ), $\mathrm{Ag}(\mathrm{I}), \mathrm{Hg}_{2}(\mathrm{II}), \mathrm{Fe}(\mathrm{III}), \mathrm{Cu}(\mathrm{I})$ and $\mathrm{Cu}(\mathrm{II})$ is thermodynamically feasible. Among the above metal ions, $\mathrm{Fe}(\mathrm{III})$ and $\mathrm{Cr}(\mathrm{VI})$ can only be reduced to $\mathrm{Fe}(\mathrm{II})$ and 


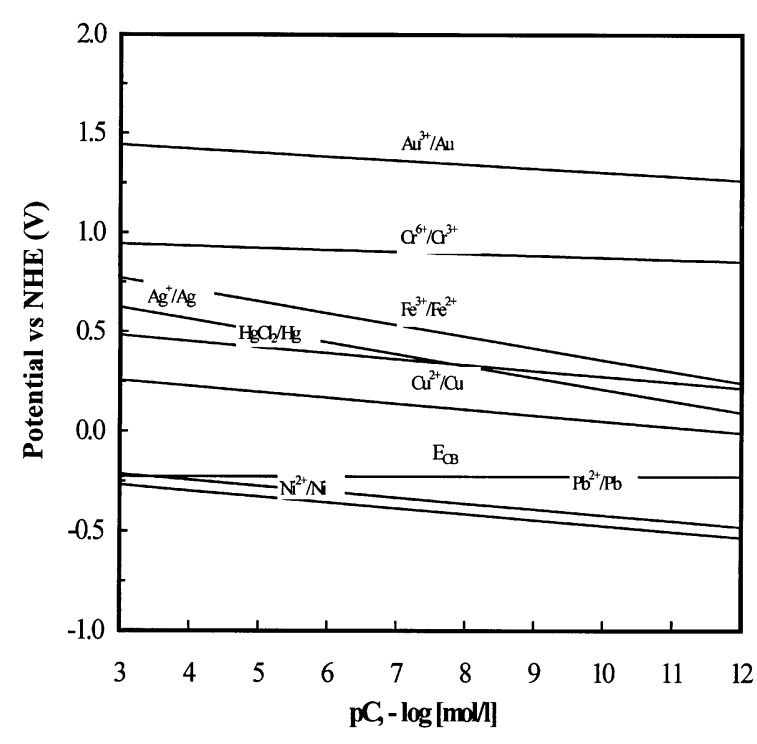

Fig. 2. Position of conduction band of $\mathrm{TiO}_{2}$ (anatase) together with the reduction potentials of metal ions of interest at $\mathrm{pH}=3$ for different concentrations (calculated from the Nernst equation).

$\mathrm{Cr}(\mathrm{III})$, rather than ion and chromium metals, respectively, because $\mathrm{Fe}(\mathrm{II})$ and $\mathrm{Cr}$ (III) cannot be reduced further as mentioned above. It is also unlikely for $\mathrm{Pb}(\mathrm{II})$ and $\mathrm{Ni}(\mathrm{II})$ to be reduced under most conditions due to the extremely low driving force. One must also note that the reduction potential of a redox couple is concentration dependent. The influence of dissolved ion concentration on the potentials of redox couples is illustrated in Fig. 2 for the species of interest. Fig. 2 shows potential versus $\mathrm{pC}$ plot when $\mathrm{pH}$ is fixed at 3 since most of the experiments were conducted around this $\mathrm{pH}$. Similar graphs like the one shown in Fig. 2 can be constructed for different $\mathrm{pH}$ from the Nernst equation. The figure clearly shows that the driving force of the photocatalytic reduction decreases with the decrease in the concentration of dissolved ions. However, all the metal ions of interest in Fig. 2, except for $\mathrm{Pb}$ (II) and $\mathrm{Ni}(\mathrm{II})$, can be photocatalytically reduced, at least thermodynamically, to a very low concentration (down to $10^{-12} \mathrm{M}$ ). The photocatalytic reduction of $\mathrm{Pb}(\mathrm{II})$ and $\mathrm{Ni}(\mathrm{II})$ cannot occur at given conditions as shown in Fig. 2. In addition, according to Fig. 1, one may also expect that oxygen might be reduced preferentially with respect to most metal ions if it is present in solution. Therefore, if reaction is studied in solution purged with nitrogen or air, or sealed to eliminate oxygen reduction, the photocatalytic reduction efficiency of metal ions can be enhanced. Hence, oxygen generated in Eq. (5) by oxidizing water might hinder metal ion reduction by acting as electron scavenger.

In practice, however, the photocatalytic reduction rate (or to what extent they can be removed for those metal ions that can be reduced thermodynamically) is governed by the reduction kinetics. Sometimes, no measurable reduction is observed owing to the very low reduction rate even though the photocatalytic reaction is thermodynamically feasible. Therefore, under the guideline of above thermodynamic analysis, kinetic study of the photocatalytic reduction for different metal ions of interest becomes more important and meaningful.

\section{Experimental details}

\subsection{Materials}

Degussa P25 $\mathrm{TiO}_{2}$ powder is most often used in photocatalytic experiments due to its high efficiency. In this study, another brand of $\mathrm{TiO}_{2}$ catalyst, Hombikat UV100, was also used. The specifications of the two catalysts are compared in Table 1. Both, Degussa P25 provided by Degussa Company (Germany) and Hombikat UV100 provided by Sachtleben Chemie GmbH (Germany), catalysts were used without further treatment in all experiments. The physiochemical data of these two titanium dioxide catalysts were reported elsewhere (Ray \& Beenackers, 1997a; Chen \& Ray, 1998). All other chemicals used are as follows: nickel chloride $(97 \%)$, iron chloride $\left(\mathrm{Fecl}_{2} 4 \mathrm{H}_{2} \mathrm{O}, 99 \%\right)$, silver nitrate $(99.8 \%)$, copper nitrate $\left(\mathrm{Cu}\left(\mathrm{NO}_{3}\right)_{2} 3 \mathrm{H}_{2} \mathrm{O}, 99 \%\right)$ and mercury chloride $(99.5 \%)$ from Merck chemicals; Lead nitrate $(99.7 \%)$ and potassium chromate $(99+\%)$ from Baker chemicals; $\mathrm{Fe}\left(\mathrm{NO}_{3}\right)_{3} 9_{2} \mathrm{H}_{2} \mathrm{O}(99 \%)$ from Nacalai Tesqcie Inc. Tyoto; EDTA (98\%) from Fluka chemicals; salicylic acid $(99.7 \%)$ and 4-nitrophenol $(98+\%)$ from BDH chemicals. Stock solutions of different metal ions were prepared from the solid samples listed above. Water used to make up solutions was Millipore Milli-Q water.

\subsection{Experimental apparatus and procedures}

Experiments were carried out in the same photoreactor reported in our previous papers (Chen \& Ray, 1998,1999). Concentration of $\mathrm{TiO}_{2}$ was $2 \mathrm{~g} / \mathrm{l}$ in all experiments throughout the work. $\mathrm{The}^{\mathrm{TiO}_{2}}$ aqueous solution, which was circulated by a peristaltic pump (Watson Marlow, 505S), was introduced into the photoreactor tangentially between the two glass plates, and exited from the centre of the top plate. Residence time distribution of reactants in the photoreactor indicated that the tangential introduction of liquid made the reaction solution well

Table 1

A comparative study of two different commercial $\mathrm{TiO}_{2}$ catalysts

\begin{tabular}{llc}
\hline Specifications/catalyst & Degussa P25 & Hombikat UV100 \\
\hline Crystal phase & $70: 30$ anatase & $\begin{array}{c}100 \% \text { anatase } \\
<10\end{array}$ \\
Particle size $(\mathrm{nm})$ & 30 & $>250$ \\
BET surface area $\left(\mathrm{m}^{2} / \mathrm{g}\right)$ & $55 \pm 15$ & \\
\hline
\end{tabular}


mixed in the reactor (Ray \& Beenackers, 1997a). Irradiation was provided by a Philips HPR $125 \mathrm{~W}$ high-pressure mercury vapour lamp. The primary radiation of this lamp is emitted at $365 \mathrm{~nm}$, and the incident light intensity is $213 \mathrm{~W} / \mathrm{m}^{2}$. The aqueous media was equilibrated with either nitrogen or oxygen for about $20 \mathrm{~min}$ prior to irradiation. Reaction system was placed in a thermostat water bath and temperature was maintained at $303 \mathrm{~K}$. Experiments were performed at natural $\mathrm{pH}$ unless otherwise mentioned. The Cyberscan $2000 \mathrm{pH}$ meter measured solution $\mathrm{pH}$. During reaction, $5 \mathrm{ml}$ sample was taken at appropriate times. $5 \mathrm{ml}$ solution with approximately same concentration was added back to the system immediately to maintain constant reaction volume.

\subsection{Analysis}

All samples were filtered by Millex-HA membrane filter (Millipore, $0.45 \mu \mathrm{m}$ ) before analysis. The filtrate was analyzed for both TOC values by a Shimadzu TOC$5000 \mathrm{~A}$ analyzer and for metal ion concentrations by an ICP (Inductively Coupled Plasma, Perkin Elmer Optima 3000 DV). Prior to the analysis of $\mathrm{Cr}(\mathrm{VI})$, the filtrate $\mathrm{pH}$ was adjusted by $1 \mathrm{M}$ sodium hydroxide to a $\mathrm{pH}$ value of 10 and then re-filtered to remove the $\mathrm{Cr}$ (III) in form of $\mathrm{Cr}(\mathrm{OH})_{3}$. For experiments containing iron ion, a Shimadzu UV3101 PC spectrophotometer was used to measure ferric ion concentration while using salicylic acid as colouring agent. Ferrous ion concentration was, subsequently, obtained by subtracting ferric ion concentration from the total iron concentration measured by the ICP.

\section{Results and discussions}

\subsection{Blank experiments}

In order to determine whether any photochemical reductions could occur or not in the absence of $\mathrm{TiO}_{2}$, blank experiments $\left(\mathrm{TiO}_{2}\right.$ free) were carried out for $\mathrm{Ag}(\mathrm{I}), \mathrm{Hg}(\mathrm{II}), \mathrm{Cr}(\mathrm{VI}), \mathrm{Pb}(\mathrm{II})$ and $\mathrm{Cu}(\mathrm{II})$. It was observed that no reduction took place for $\mathrm{Hg}(\mathrm{II}), \mathrm{Cr}(\mathrm{VI})$, $\mathrm{Pb}$ (II) and $\mathrm{Cu}$ (II) during the 60 min of illumination. In addition, the $\mathrm{pH}$ remained unchanged throughout the irradiation. However, for $\mathrm{AgNO}_{3}$ and UV system, the concentration of $\mathrm{Ag}(\mathrm{I})$ decreased during the UV illumination. The solution when illuminated turned from white to brown immediately. This is because silver nitrate can easily decompose to silver according to Eq. (8) once exposed to light, even if the light is not an ultraviolet light:

$\mathrm{AgNO}_{3} \stackrel{\text { light }}{\longrightarrow} \mathrm{Ag}+2 \mathrm{NO}_{2}+\mathrm{O}_{2}$.

\subsection{Adsorption and photocatalytic reduction}

Table 2 summarizes results for the removal of the eight investigated metal ions in $\mathrm{TiO}_{2}$ suspended aqueous solution for two different brands of photocatalysts. Experiments were carried out under identical conditions for adsorption and photocatalytic reduction. Initial concentration of metal ions was about $0.6 \mathrm{mM}$. $\mathrm{TiO}_{2}$ dosage was $2 \mathrm{~g} / 1$. Adsorption occurred first after $\mathrm{TiO}_{2}$ was dispersed into the aqueous solution containing metal ions. This process is reversible and does not require light illumination. In this study, no attempt was made to adjust the $\mathrm{pH}$ of the solution and experiments were carried out in natural $\mathrm{pH}$ for both physical adsorption and photocatalytic reduction except for $\mathrm{Cr}(\mathrm{VI})$, where $\mathrm{pH}$ was adjusted to 3.0 by $\mathrm{HCl}$. In all the above experiments, 4-nitrophenol with concentration of $0.2 \mathrm{mM}$ was used as reductant. Results demonstrated that both photocatalysts had very high capacities for Fe(III) adsorption, and as shown in Fig. 3, adsorption equilibrium of $\mathrm{Fe}$ (III) on both photocatalysts could be established within few minutes. However, removal of other metal ions by physical adsorption was less than $20 \%$ (see Table 2) for all species investigated except for the adsorption of $\mathrm{Cr}(\mathrm{VI})$ on UV100 $\mathrm{TiO}_{2}$.

As for the photocatalytic reduction, Fe(III) could be very effectively reduced by both photocatalysts as shown in Fig. 3. For all other metal ions investigated, Hombikat UV100 exhibited extremely low or even no reactivity. By contrast, Degussa P25 exhibited good activity for photocatalytic reduction of $\mathrm{Ag}(\mathrm{I}), \mathrm{Cr}(\mathrm{VI})$ and $\mathrm{Hg}(\mathrm{II})$, besides $\mathrm{Fe}(\mathrm{III})$ (see Fig. 4). However, no reduction of $\mathrm{Cu}(\mathrm{II})$, $\mathrm{Ni}(\mathrm{II})$ and $\mathrm{Fe}(\mathrm{II})$ was observed even though photocatalytic reduction of $\mathrm{Cu}(\mathrm{II})$ is thermodynamically feasible.

Table 2

Removal of dissolved metal ions by adsorption and photocatalytic reduction

\begin{tabular}{|c|c|c|c|c|}
\hline \multirow[b]{2}{*}{ Metal } & \multicolumn{2}{|c|}{$\begin{array}{l}\text { Adsorption } \\
\text { (dark reaction) } \\
\text { over } \mathrm{TiO}_{2}(\%)^{\mathrm{a}}\end{array}$} & \multicolumn{2}{|c|}{$\begin{array}{l}\text { Photocatalytic } \\
\text { reduction with } \\
\mathrm{N}_{2} \text { purged }(\%)^{\mathrm{b}}\end{array}$} \\
\hline & P25 & UV100 & P25 & UV100 \\
\hline $\operatorname{Ag}(\mathrm{I})$ & 11.4 & 14.1 & 99.7 & 46.62 \\
\hline $\mathrm{Pb}(\mathrm{II})$ & 12.3 & 10.5 & 27.2 & 8.6 \\
\hline $\operatorname{Hg}(\mathrm{II})$ & 10.4 & 13.3 & 70.0 & 18.6 \\
\hline $\mathrm{Ni}(\mathrm{II})^{\mathrm{c}}$ & $\mathrm{N}$ & $\mathrm{N}$ & $\mathrm{N}$ & $\mathrm{N}$ \\
\hline $\mathrm{Cu}(\mathrm{II})$ & $\mathrm{N}$ & 7.1 & $\mathrm{~N}$ & 14.0 \\
\hline $\mathrm{Cr}(\mathrm{VI})^{\mathrm{d}}$ & 16.7 & 28.3 & 79.1 & 36.8 \\
\hline $\mathrm{Fe}(\mathrm{III})$ & 92.0 & 95.2 & 100 & 100 \\
\hline $\mathrm{Fe}(\mathrm{II})$ & 5.1 & 6.4 & 6.2 & 5.4 \\
\hline
\end{tabular}

\footnotetext{
${ }^{\text {a }}$ Removal was measured after $48 \mathrm{~h}$ of static adsorption.

${ }^{\mathrm{b}}$ Removal was measured after 65 min of illumination.

${ }^{\mathrm{c}} N$ stands for no observable difference in concentration before and after treatment.

${ }^{\mathrm{d}} \mathrm{pH}$ was adjusted to 3 .
} 


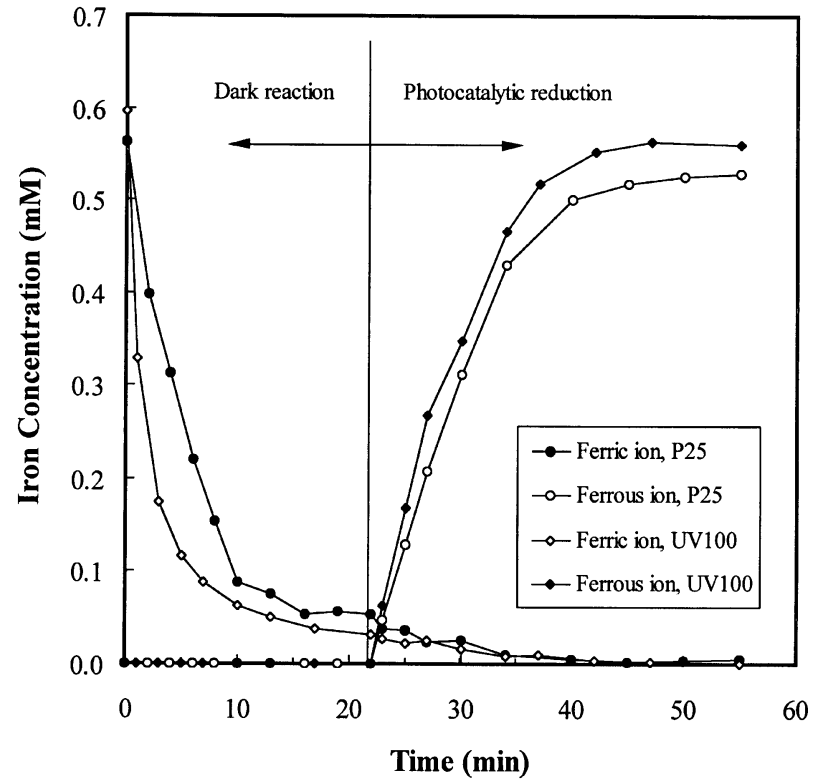

Fig. 3. Dark reaction (adsorption) and photocatalytic reduction of $\mathrm{Fe}(\mathrm{III})$ in $\mathrm{P} 25$ and $\mathrm{UV} 100 \mathrm{TiO}_{2}$ suspensions containing $0.2 \mathrm{mM} 4-\mathrm{NP}$ (experimental conditions: $I=18.1 \mathrm{~mW} / \mathrm{cm}^{2},\left[\mathrm{TiO}_{2}\right]=0.2 \mathrm{wt} \%$, $T=298 \mathrm{~K}, \mathrm{O}_{2}$ saturated, $\mathrm{pH}$ natural).

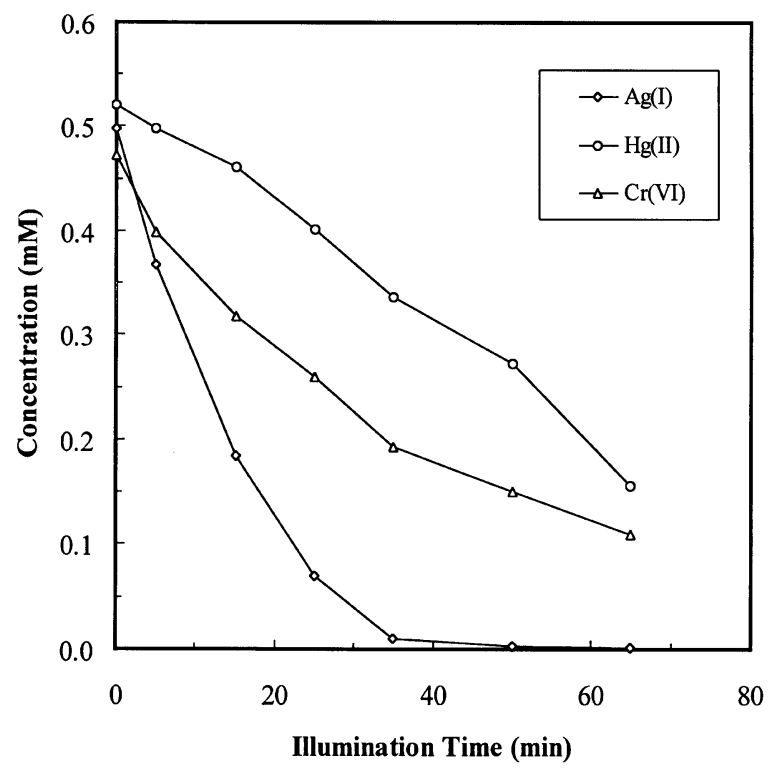

Fig. 4. Photocatalytic reduction of metal ions in $\mathrm{P} 25 \mathrm{TiO}_{2}$ suspensions containing $0.2 \mathrm{mM}$ 4-NP (experimental conditions: $V_{L}=1.45 \times$ $10^{-4} \mathrm{~m}^{3}, I=18.3 \mathrm{~mW} / \mathrm{cm}^{2},\left[\mathrm{TiO}_{2}\right]=0.2 \mathrm{wt} \%, T=298 \mathrm{~K}, \mathrm{~N}_{2}$ saturated, $\mathrm{pH}$ natural).

$\mathrm{Ag}(\mathrm{I})$ and $\mathrm{Hg}(\mathrm{II})$ could be reduced to $\mathrm{Ag}^{0}$ and $\mathrm{Hg}^{0}$, respectively, and subsequently were deposited onto the catalyst surface (Herrmann et al., 1988; Serpone et al., 1988). But for $\mathrm{Fe}(\mathrm{III})$ and $\mathrm{Cr}(\mathrm{VI})$, the ultimate reduction products obtained were $\mathrm{Fe}(\mathrm{II})$ and $\mathrm{Cr}(\mathrm{III})$, respectively. Based on the thermodynamic analysis, photocatalytic reduction of $\mathrm{Pb}(\mathrm{II})$ is impossible. However, its concentration in aqueous solution did decrease with the illumination time in our experiments, although it decreased at a very slow rate. Tanaka et al. (1986) reported that $\mathrm{PbO}_{2}$ was identified in $\mathrm{TiO}_{2}$ suspensions containing $\mathrm{Pb}$ (II) when illuminated with UV light. The metal ion was considered to be oxidized by the positive hole according to the following reaction:

$\mathrm{Pb}^{2+}+2 \mathrm{H}_{2} \mathrm{O}+2 \mathrm{~h}^{+} \longrightarrow \mathrm{PbO}_{2}+4 \mathrm{H}^{+}$.

\subsection{Influence of iron ion}

In open literature to date, very few papers dealt with photoreduction of multi-metal ion system. Herrmann et al. (1988) investigated the photocatalytic reduction of silver ion in the presence of $\mathrm{Cu}(\mathrm{II})$. They found that silver could be recovered unaided irrespective of the presence of copper ion, and no reduction of copper was observed as well. Ferric ion is extensively present in both natural environment and industrial effluents. But, no work reported its influence on the photocatalytic reduction of other metal ions. In this study, we found that the presence of ferric ion had a significant inhibiting effect on the photocatalytic reduction of $\mathrm{Hg}(\mathrm{II})$, due to its very high adsorption capacity on $\mathrm{TiO}_{2}$ (as reported in Table 2, $92 \%$ of ferric ions were absorbed in a $0.2 \mathrm{wt} \% \mathrm{TiO}_{2}$ suspensions), and readily being reduced by the conduction band electrons. Fig. 5 illustrates the time course of photocatalytic reduction of $\mathrm{Hg}(\mathrm{II})$ to $\mathrm{Hg}$ in the absence (and presence) of ferric ions in $\mathrm{P} 25 \mathrm{TiO}_{2}$ suspensions. When no $\mathrm{Fe}(\mathrm{III})$ is present, reduction of $\mathrm{Hg}$ (II) to $\mathrm{Hg}$ was slow and could not be completely reduced as indicated by open circle in Fig. 5. However, when Fe(III) was added into the system, reduction of $\mathrm{Hg}(\mathrm{II})$ to $\mathrm{Hg}$ was almost quenched in the first $15 \mathrm{~min}$ where ferric ion was present at relative high concentration, and we observed reduction of $\mathrm{Fe}$ (III) to Fe(II) (see Fig. 5). The reduction of $\mathrm{Hg}$ (II) to $\mathrm{Hg}$ started only after the concentration of $\mathrm{Fe}(\mathrm{III})$ was reduced to a low value. The preferential reduction of $\mathrm{Fe}(\mathrm{III})$ to $\mathrm{Fe}(\mathrm{II})$ over $\mathrm{Hg}$ (II) to $\mathrm{Hg}$ occurs due to strong adsorption of $\mathrm{Fe}(\mathrm{III})$ over $\mathrm{Hg}$ (II) on $\mathrm{P} 25$ $\mathrm{TiO}_{2}$ catalyst (see Table 2). As shown in Fig. 3, photocatalytic reduction of $\mathrm{Fe}$ (III) on catalyst surface was very fast and efficient, and evidently could be completely reduced within few minutes. The above results indicate that photocatalytic reduction of metal ions, both $\mathrm{Fe}(\mathrm{III})$ and $\mathrm{Hg}(\mathrm{II})$, occur on the surface of the catalyst rather than in the bulk solution, if not completely, at least predominantly. The reduction of $\mathrm{Hg}$ (II) resumed after most of the ferric ions had been converted to ferrous ion. Moreover, a close scrutiny of Fig. 5 reveals that compared with the experiment without ferric ion, the reduction of $\mathrm{Hg}(\mathrm{II})$ was accelerated when the concentration of ferrous ion increased through formation from $\mathrm{Fe}(\mathrm{III})$. It was observed that $\mathrm{Hg}(\mathrm{II})$ could be reduced to much lower 


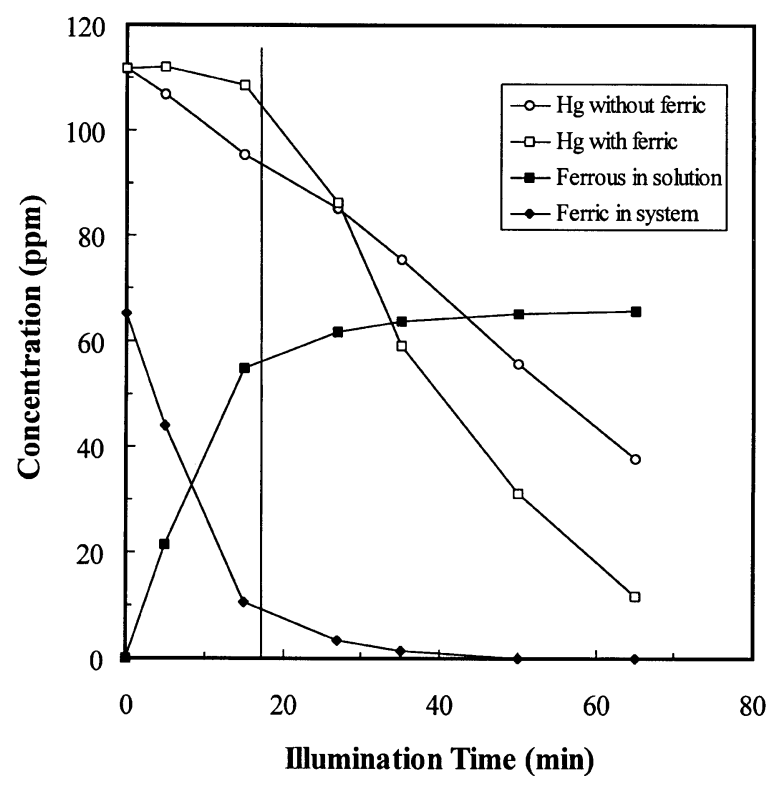

Fig. 5. Influence of iron ion on the reduction of $\mathrm{Hg}(\mathrm{II})$ in $\mathrm{P} 25 \mathrm{TiO}_{2}$ suspensions containing $0.2 \mathrm{mM} 4-\mathrm{NP}$ (experimental conditions: $V_{L}=$ $1.45 \times 10^{-4} \mathrm{~m}^{3}, I=18.3 \mathrm{~mW} / \mathrm{cm}^{2},\left[\mathrm{TiO}_{2}\right]=0.2 \mathrm{wt} \%, T=298 \mathrm{~K}, \mathrm{~N}_{2}$ saturated, $\mathrm{pH}$ natural).

concentration in the presence of $\mathrm{Fe}(\mathrm{III})$ as indicated by the open square in Fig. 5. It suggests that ferrous ion had a promoting effect on the reduction of $\mathrm{Hg}(\mathrm{II})$. This effect can be explained by the following reaction. In the absence of $\mathrm{Fe}(\mathrm{III})$ ion, $\mathrm{Hg}$ (II) was reduced according to

$\mathrm{Hg}^{2+}+2 \mathrm{e}^{-} \stackrel{\mathrm{TiO}_{2}, \mathrm{UV}}{\longrightarrow} \mathrm{Hg}$.

However, when Fe(III) was added, reaction (11) preferentially took place (due to stronger adsorption of $\mathrm{Fe}$ (III) on $\mathrm{TiO}_{2}$ ) over reaction (10):

$\mathrm{Fe}^{3+}+\mathrm{e}^{-} \stackrel{\mathrm{TiO}_{2}, \mathrm{UV}}{\longrightarrow} \mathrm{Fe}^{2+}$.

Moreover, when $\mathrm{Fe}(\mathrm{II})$ was formed in appreciable amount, an additional reaction occurred given by the following reaction:

$\mathrm{Hg}^{2+}+2 \mathrm{Fe}^{2+} \stackrel{\mathrm{uv}}{\longrightarrow} \mathrm{Hg}+2 \mathrm{Fe}^{3+}$.

Reaction (12) was confirmed in this study experimentally. Homogeneous reaction between $\mathrm{Hg}(\mathrm{II})$ and $\mathrm{Fe}(\mathrm{II})$ under UV illumination demonstrated that $\mathrm{Hg}(\mathrm{II})$ concentration decreased with illumination time. Furthermore, Fe(III) was detected in reaction samples. When salicylic acid was added into the reaction sample, it immediately turned to purple. The above reactions form a redox cycle that favours the reduction of mercury in heterogeneous photocatalytic system when ferric ion is present. Both reactions (10) and (12) make contribution to the reduc- tion of $\mathrm{Hg}(\mathrm{II})$, but which one is predominant depends on the relative concentration of mercury to iron.

\subsection{Influence of dissolved oxygen}

In photocatalytic reduction systems, dissolved oxygen has significant influence on the reduction rate. Dissolved oxygen competes with photogenerated electrons on the surface of the photocatalyst, which is detrimental to the photocatalytic reduction of metal ions. Therefore, one can expect that in the absence of dissolved oxygen, by purging the solution with nitrogen, a higher removal rate of metal ion might be achieved. In order to investigate the influence of dissolved oxygen, experiments were carried out under three different reaction atmospheres, namely, oxygen saturated, air equilibrated and nitrogen purged. When experiments were performed with metal ions using Hombikat UV100 catalyst, it was observed that the reduction rate was not affected whether the solution was purged with nitrogen or oxygen. This is most likely due to the extremely low activity of the catalyst (see Table 2). It should be noted that removal of silver in Hombikat UV100 suspensions did not result from the photocatalytic reaction. It was due to the direct decomposition of silver nitrate through reaction (8), as the result was in good agreement with blank experiments.

However, Photocatalytic reduction by $\mathrm{P} 25 \mathrm{TiO}_{2}$ was influenced by the presence of dissolved oxygen. This is shown in Fig. 6. The figure clearly exhibits that the photocatalytic reduction of $\mathrm{Ag}(\mathrm{I})$ and $\mathrm{Hg}(\mathrm{II})$ in Degussa P25 was altered, whereas the presence of dissolved oxygen did not inhibit the reduction of Fe(III). The influence was particularly pronounced for $\mathrm{Hg}(\mathrm{II})$ as the presence of dissolved oxygen significantly inhibited its reduction. However, no significant negative effect was evidenced for the reduction of $\mathrm{Cr}(\mathrm{VI})$. This is probably because of its very high reduction driving force. According to Fig. 1, reduction potential of $\mathrm{Cr}(\mathrm{VI})$ (vs. NHE) is as high as $0.93 \mathrm{~V}($ at $\mathrm{pH}=3)$, and therefore, the negative effect from the dissolved oxygen may be negligible. However, influence of dissolved oxygen was observed for the reduction of silver ions for which reduction potential (vs. NHE) is $0.8 \mathrm{~V}$ compared to $0.93 \mathrm{~V}$ for $\mathrm{Cr}(\mathrm{VI})$, as the driving force for reduction is lower. The pronounced influence of dissolved oxygen for reduction of $\mathrm{Hg}(\mathrm{II})$ compared to $\mathrm{Ag}(\mathrm{I})$ may be explained as follows: although $\varphi_{\mathrm{Hg}^{2+}}^{0} / \mathrm{Hg}$ is as high as $0.85 \mathrm{~V}$ (vs. NHE) in $0.6 \mathrm{mM} \mathrm{HgCl}_{2}$ aqueous solution, $98 \%$ of mercury is present in the form of neutral $\mathrm{HgCl}_{2}$ species (Sawyer, McCarty, \& Parkin, 1994) rather than $\mathrm{Hg}^{2+}$. The reduction potential of $\mathrm{HgCl}_{2}$ (vs. NHE), $\varphi_{\mathrm{HgCl}_{2} / \mathrm{Hg}}^{0}$, is as low as $0.41 \mathrm{~V}$. Consequently, the presence of dissolved oxygen had more significant negative effect on the reduction of $\mathrm{Hg}(\mathrm{II})$ than that of $\mathrm{Ag}(\mathrm{I})$. As for $\mathrm{Fe}(\mathrm{III})$, although its reduction potential is not as high as that of $\mathrm{Cr}(\mathrm{VI}), \varphi_{\mathrm{Fe}^{3+}}^{0} / \mathrm{Fe}^{2+}=0.77 \mathrm{~V}$ (vs. NHE), its strong adsorption on the photocatalyst favours its reduction. 


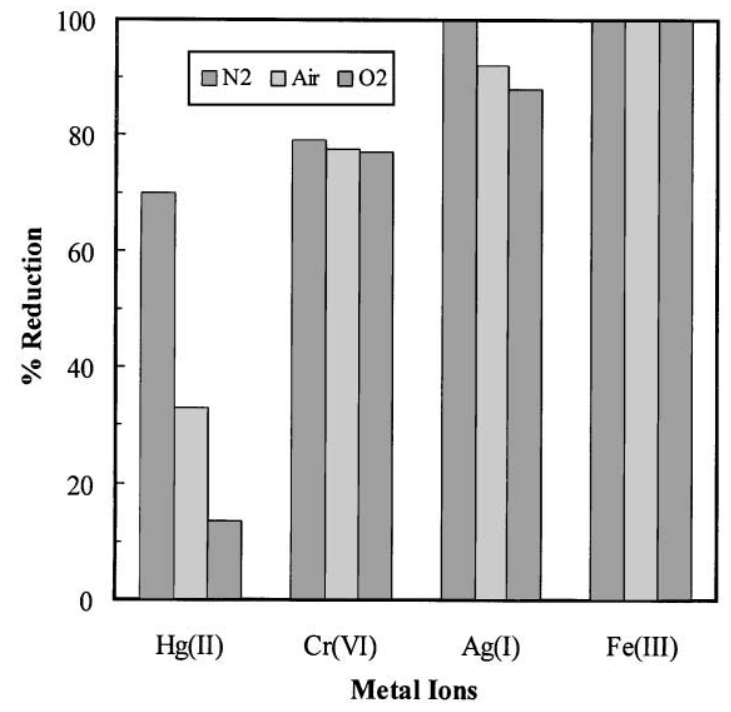

Fig. 6. Influence of dissolved oxygen on the reduction of metal ions in $\mathrm{P} 25 \mathrm{TiO}_{2}$ suspensions (experimental conditions: $V_{L}=1.45 \times 10^{-4} \mathrm{~m}^{3}$, $I=17.7 \sim 18.3 \mathrm{~mW} / \mathrm{cm}^{2}, \quad C_{0}=0.6 \mathrm{mM}, \quad\left[\mathrm{TiO}_{2}\right]=0.2 \mathrm{wt} \%, \quad[4-$ $\mathrm{NP}]=0.2 \mathrm{mM}, T=298 \mathrm{~K})$.

Therefore, photocatalytic reduction of ferric ion was not at all affected by the dissolved oxygen.

In literature, however, the influence of dissolved oxygen on the reduction rate of $\mathrm{Cr}(\mathrm{VI})$ has led to controversial results. Negative effects have been reported in some papers (Munoz \& Domenech, 1990; Lin, Wei, \& Rajeshwar, 1993). Whereas, when the solution is purged with nitrogen, positive influence was observed by (Khalil et al., 1998). Moreover, no effect has been found by other authors (Aguado, Gimenez, \& Cervera-March, 1991). The discrepancies in the result is due to varying solution conditions under which experiments were performed by different researchers.

\subsection{Influence of the reductants}

In the absence of other organic species, the conjugate oxidation reaction of metal ion reduction is the electrochemical oxidation of water. This is a kinetically slow four-electron process (Eq. (5)), and the competing recombination of the photogenerated holes and electrons plays an active inhibiting role (Navio et al., 1998). Therefore, one can expect that the addition of sacrificial electron donors such as suitable organic substrates may accelerate the photocatalytic reduction of metal ions. As a consequence, photocatalytic reduction on $\mathrm{TiO}_{2}$ in metalorganics- $\mathrm{TiO}_{2}$ must be more efficient than that in metal- $\mathrm{TiO}_{2}$ system resulting from the accelerating effect by the preferential photocatalytic oxidation of the organics. In such metal-organics- $\mathrm{TiO}_{2}$ coexisted system, organic species accepts holes from valence band either directly or indirectly, and subsequently, is oxidized (Eq. (3) and (4)) thereby suppressing the electron-hole recom-

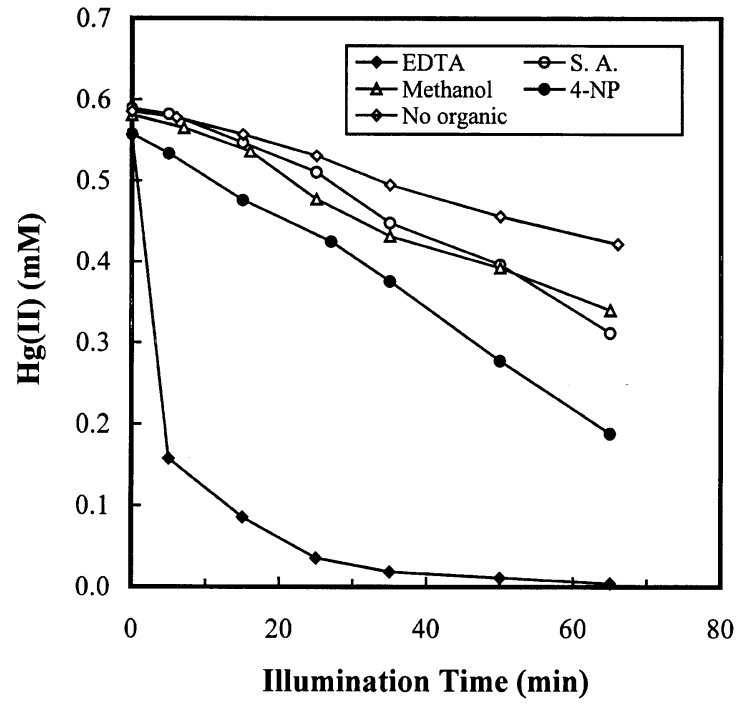

Fig. 7. Influence of reductants $(0.2 \mathrm{mM})$ on the reduction of mercury in $\mathrm{P} 25 \mathrm{TiO}_{2}$ suspensions (experimental conditions: $V_{L}=1.45 \times 10^{-4} \mathrm{~m}^{3}$, $I=17.7-18.3 \mathrm{~mW} / \mathrm{cm}^{2},\left[\mathrm{TiO}_{2}\right]=0.2 \mathrm{wt} \%, T=298 \mathrm{~K}, \mathrm{~N}_{2}$ saturated, $\mathrm{pH}$ natural).

bination, and increasing the reduction efficiency. In this study, effect of four reductants (4-nitrophenol, methanol, salicylic acid and EDTA) was investigated. The influence of these reductants on the photocatalytic reduction of mercury is shown in Fig. 7. Indeed, it was found that the presence of all four organic species has promoting effect on the photcatalytic reduction of $\mathrm{Hg}(\mathrm{II})$. It was observed that 4-nitrophenol, methanol and salicylic acid could increase the reduction, but not significantly. However, the presence of EDTA enhanced the reduction in suspended Degussa P25 $\mathrm{TiO}_{2}$ solution very effectively. EDTA is a strong chelating agent and may form stable complex with $\mathrm{Hg}(\mathrm{II})$ through the reaction

$\mathrm{Hg}^{2+}+\mathrm{EDTA} \rightarrow[\mathrm{Hg} \cdot \mathrm{EDTA}]_{\text {complex }}$.

Therefore, it is likely that the fast removal of $\mathrm{Hg}$ (II) may be contributed by the strong adsorption of mercury complex over $\mathrm{P} 25 \mathrm{TiO}_{2}$ rather than by the photocatalytic reduction. In order to rule out this possibility, physical adsorption experiment of $\mathrm{Hg}(\mathrm{II})$ was conducted in solution containing $0.2 \mathrm{mM}$ EDTA. $\mathrm{Hg}(\mathrm{II})$ removal observed by dark adsorption was only $11.5 \%$, very close to that observed in $0.2 \mathrm{mM}$ 4-nitrophenol solution (Table 2). Hence, it may be concluded that EDTA is a very effective electron donor (or hole acceptor) in photocatalytic systems. Prairie et al. (1993) proposed that two different electron donating process occurred for different organic substrates during reaction, namely, direct and indirect donation of electron. In the former case, electrons from organics are directly filled to the valence band, thereby attenuating the electron-hole recombination, and leaving more conduction band electrons available for reduction of metal ions. As a result, addition of these types of 


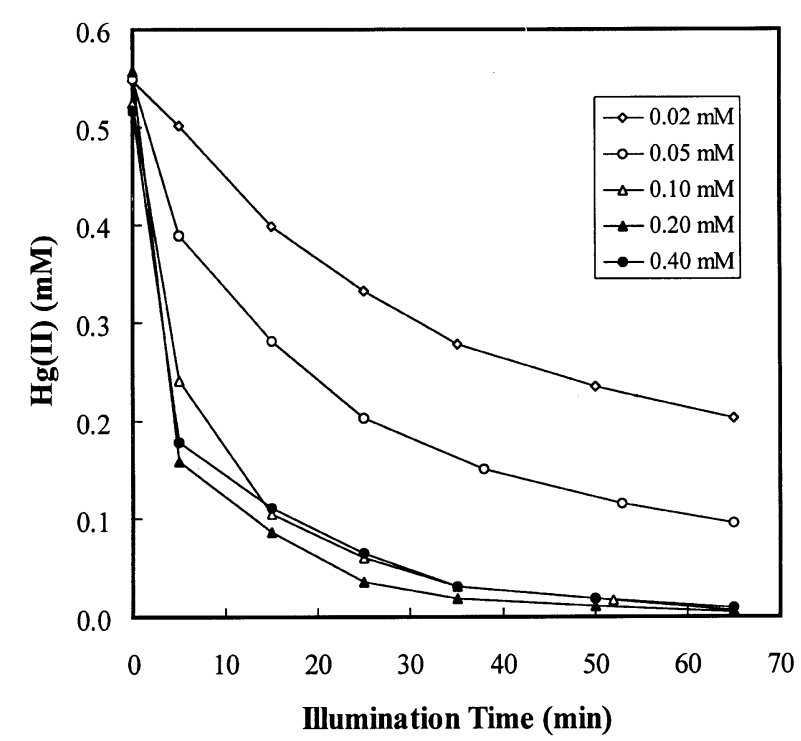

Fig. 8. Influence of EDTA concentration on the mercury reduction in P25 $\mathrm{TiO}_{2}$ suspensions (experimental conditions: $V_{L}=1.45 \times 10^{-4} \mathrm{~m}^{3}$, $I=18.1 \mathrm{~mW} / \mathrm{cm}^{2},\left[\mathrm{TiO}_{2}\right]=0.2 \mathrm{wt} \%, T=298 \mathrm{~K}, \mathrm{~N}_{2}$ saturated, $\mathrm{pH}$ natural).

organics has much more pronounced effect on the reduction of metal ions. In the latter case, holes are filled only through the formation of hydroxyl radicals, and these radicals are subsequently consumed by the oxidation of the added organics. Thus, organics in this class influence the reduction of metal ions indirectly, resulting in less promoting effect. Therefore, it is probable that 4-nitrophenol, salicylic acid and methanol accelerate the photocatalytic reduction by donating electrons indirectly, while EDTA donate electrons directly. It was also found that above promiting effect of EDTA is concentration dependent. Fig. 8 illustrates the influence of EDTA concentration on the reduction rate of $\mathrm{Hg}(\mathrm{II})$. As expected, the reduction rate increased with the increase of organic substrate concentration from 0.02 to $0.2 \mathrm{mM}$. However, inhibiting effect was observed at much higher concentration $(0.4 \mathrm{mM})$. During the oxidation of EDTA, intermediates were formed as evidenced by the grey colour of the solution. The concentration of intermediates increased with the initial EDTA concentration. When EDTA concentration was beyond a certain level (about $0.4 \mathrm{mM}$ ), it was observed that the reaction solution is dark grey in colour, which subsequently blocked the $\mathrm{TiO}_{2}$ catalyst from receiving UV illumination. This resulted in the inhibition of reduction rate of $\mathrm{Hg}(\mathrm{II})$ in the presence of EDTA of concentration greater than about $0.4 \mathrm{mM}$.

\section{Conclusions}

Photocatalytic reduction of environmentally important metal ions over Degussa P25 and Hombikat UV100
$\mathrm{TiO}_{2}$ catalysts was investigated. UV100 $\mathrm{TiO}_{2}$ did not exhibit any activity in the photocatalytic reduction of the metal ions studied except for $\mathrm{Fe}(\mathrm{III}) \mathrm{Hg}(\mathrm{II}), \mathrm{Ag}(\mathrm{I}), \mathrm{Fe}(\mathrm{III})$ and $\mathrm{Cr}(\mathrm{VI})$ could be efficiently reduced over $\mathrm{P} 25 \mathrm{TiO}_{2}$. After reduction, mercury and silver were deposited onto $\mathrm{TiO}_{2}$ while iron and chromium remained in solution in form of ferrous ion and trivalent chromium, respectively. Ferric ion had very high adsorption capacities on both photocatalysts, and its presence prevented mercury ion from undergoing photocatalytic reduction. It was observed that the photocatalytic reduction occurred on the surface of the catalyst rather than in the bulk solution. Presence of ferrous ion improved the reduction rate of mercury. Dissolved oxygen, acting as electron acceptor, significantly inhibited the photocatalytic reduction of metal ions, whose reduction potentials are low. The presence of organic reductants could promote photocatalytic reduction. EDTA was found out to be the most efficient promoter among the four organic species studied. Its promoting effect is probably through the direct transfer of electrons to the valence band of semiconductor photocatalyst. The influence was also observed to be concentration dependent and $0.2 \mathrm{mM}$ EDTA was found out to be the optimal concentration for the reduction of mercury.

\section{Acknowledgements}

The authors like to acknowledge the financial support from the National University of Singapore and Environmental Technology (ET) Enterprise, Singapore.

\section{References}

Aguado, M. A., Gimenez, J., \& Cervera-March, S. (1991). Continuous photocatalytic treatment of $\mathrm{Cr}(\mathrm{VI})$ effluents with semiconductor powders. Chemical Engineering and Communication, 104, 71-85.

Angelidis, T. N., Koutlemani, M., \& Poulios, I. (1998). Kinetic study of the photocatalytic recovery of $\mathrm{Pt}$ from aqueous solution by $\mathrm{TiO}_{2}$, in a closed-loop reactor. Applied Catalysis B: Environmental, 16 , 347-357.

Bideau, M., Claudel, B., Faure, L., \& Rachimoellah, M. (1990). Photooxidation of formic-acid by oxygen in the presence of titaniumdioxide and dissolved copper ions-oxygen-transfer and reaction kinetics. Chemical Engineering and Communication, 93, 167-197.

Chen, D. W., \& Ray, A. K. (1998). Photodegradation kinetics of 4-nitrophenol in $\mathrm{TiO}_{2}$ suspension. Water Research, 32, 3223-3234.

Chen, D. W., \& Ray, A. K. (1999). Photocatalytic kinetics of phenol and its derivatives over UV irradiated $\mathrm{TiO}_{2}$. Applied Catalysis B: Environmental, 23, 143-157.

Chen, D. W., Sivakumar, M., \& Ray, A. K. (2000a). Heterogeneous photocatalysis in environmental remediation, Developmental Chemical Engineering and Mineral Processes, 8(5/6), 505-550.

Chen, D. W., Fengmei, L., \& Ray, A. K. (2000b). Effect of mass transfer and catalyst layer thickness on photocatalytic reaction. A.I.Ch.E. Journal, 46(5), 1034-1045. 
Foster, N. S., Noble, R. D., \& Koval, C. A. (1993). Reversible photoreductive deposition and oxidative dissolution of copper ions in titanium dioxide aqueous suspension. Environmental Science and Technology, 27, 350-358.

Fu, H., Lu, G., \& Li, S. (1998). Adsorption and photo-induced reduction of $\mathrm{Cr}(\mathrm{VI})$ ion in $\mathrm{Cr}(\mathrm{VI})-4-\mathrm{CP}$ aqueous system in the presence of $\mathrm{TiO}_{2}$ as photocatalyst. Journal of Photochemistry and Photobiology A: Chemistry, 114, 81-88.

Herrmann, J. M., Disdier, J., \& Pichat, P. (1988). Photocatalytic deposition of silver on powder titania: Consequences for the recovery of silver. Journal of Catalysis, 113, 72-81.

Khalil, L. B., Mourad, W. E., \& Rophael, M. W. (1998). Photocatalytic reduction of environmental pollutant $\mathrm{Cr}(\mathrm{VI})$ over some semiconductors under UV/visible light illumination. Applied Catalysis B: Environmental, 17, 267-273.

Lin, W. -Y., Wei, C., \& Rajeshwar, K. (1993). Photocatalytic reduction and immobilization of hexavalent chromium at titanium-dioxide in aqueous basic-media. Journal of Electrochemical Society, 140, 2477.

Mukherjee, P. S., \& Ray, A. K. (1999). Major challenges in the design of a large-scale photocatalytic reactor for water treatment. Chemical Engineering Technology, 22(3), 253-260.

Munoz, J., \& Domenech, X. (1990). $\mathrm{TiO}_{2}$ catalyzed reduction of $\mathrm{Cr}(\mathrm{VI})$ in aqueous-solutions under ultraviolet illumination. Journal of Applied Electrochemistry, 20, 518-521.

Navio, J. A., Colon, G., Trillas, M., Peral, J., Domenech, X., Testa, J. J., Padron, J., Rodriguez, D., \& Litter, M. I. (1998). Heterogeneous photocatalytic reactions of nitrite oxidation and $\mathrm{Cr}(\mathrm{VI})$ reduction on iron-doped titania prepared by the wet impregnation method. Applied Catalysis B: Environmental, 16, 187-196.

Periyathamby, U., \& Ray, A. K. (1999). Reactive flow modeling on a distributive computing environment. Chemical Engineering Technology, 22(10), 881-888.

Prairie, M. R., Evans, L. R., Stange, B. M., \& Martinez, S. L. (1993). An investigation of $\mathrm{TiO}_{2}$ photocatalysis for the treatment of water contaminated with metals and organic chemicals. Environmental Science Technology, 27, 1776-1782.

Ray, A. K., \& Beenackers, A. A. C. M. (1997a). Novel swirl-flow reactor for kinetic studies of semiconductor photocatalysis. A.I.Ch.E. Journal, 43, 2571-2578.

Ray, A. K., \& Beenackers, A. A. C. M. (1997b). Development of a new photocatalytic reactor for water purification. Catalysis Today, 40, 73-83.

Ray, A. K., \& Beenackers, A. A. C. M. (1998). Photocatalytic reactor for water purification. A.I.Ch.E. Journal, 44, 477-483.
Ray, A. K. (1998). A new photocatalytic reactor for destruction of toxic water pollutants by advanced oxidation process. Catalysis Today, 44, 357-368.

Ray, A. K. (1999). Design, modeling and experimentation of a new large-scale photocatalytic reactor for water treatment. Chemical Engineering Science, 54(15-16), 3113-3125.

Ray, A. K. (2000). Design and development of two large-scale photocatalytic reactors for water treatment of toxic chemicals in wastewater. In M. A. Abraham, R. P. Hesketh (Eds.), Reaction engineering for pollution prevention (pp. 151-171) Amesterdam: Elsevier Science.

Reiche, H., Dunn, W. W., \& Bard, A. J. (1979). Heterogeneous photocatalytic and photosynthetic deposition of $\mathrm{Cu}$ on $\mathrm{TiO}_{2}$ and $\mathrm{WO}_{3}$ powders. Journal of Physical Chemistry, 83, 2248-2251.

Sawyer, C. N., McCarty, P. L., \& Parkin, G. F. (1994). Chemistry for environmental engineering. New york: McGraw-Hill.

Selli, E., Giorgi, A. D., \& Bidoglio, G. (1996). Humic acid-sensitized photoreduction of $\mathrm{Cr}(\mathrm{VI})$ on $\mathrm{ZnO}$ particles. Environmental Science Technology, 30, 598-604.

Serpone, N., Ah-You, Y. K., Tran, T. P., Harris, R., Pelizzetti, E., \& Hidaka, H. (1987). AM1 simulated sunlight photoreduction of $\mathrm{Hg}$ (II) and $\mathrm{CH}_{3} \mathrm{Hg}(\mathrm{II})$ chloride salts from aqueous suspensions of titanium dioxide. Solar Energy, 39, 491-498.

Serpone, N., Boragarello, E., \& Pelizzetti, E. (1988). Photoreduction and photodegradation of inorganic pollutants: II. Selective reduction and recovery of $\mathrm{Au}, \mathrm{Pt}, \mathrm{Pd}, \mathrm{Rh}, \mathrm{Hg}$ and $\mathrm{Pb}$. In $\mathrm{M}$. Schiavelb (Ed.), Photocatalysis and Environment, Trends and Applications, (pp. 527-565), Dordrecht: Kluwer.

Tanaka, K., Harada, K., \& Murata, S. (1986). Photocatalytic deposition of metal ions onto $\mathrm{TiO}_{2}$ powder. Solar Energy, 36, 159-161.

Tennakone, K., \& Wijayantha, K. G. U. (1998). Heavy-metal extraction from aqueous medium with an immobilized $\mathrm{TiO}_{2}$ photocatalyst and a solid sacrificial agent. Journal of Photochemistry and Photobiology A: Chemistry, 113, 89-92.

Wang, S., Wang, Z., \& Zhuang, Q. (1992). Photocatalytic reduction of the environmental pollutant $\mathrm{Cr}(\mathrm{VI})$ over a cadmium sulphide powder under visible light illumination. Applied Catalysis B: Environmental, 1, 257-270.

Wang, Y. -Y., \& Wan, C. -C. (1994). Investigation of photoelectrochemical reduction of cupric ions over $\mathrm{TiO}_{2}$ in the presence of methanol. Journal of Photochemistry and Photobiology A: Chemistry, 84, 195-202.

Ward, M. D., White, J. R., \& Bard, A. J. (1983). Electrochemical investigation of the energetics of particulate titanium dioxide photocatalysts. The methyl viologen-acetate system. Journal of American Chemical Society, 105, 27-31. 